\section{MECHANICAL VENTILATION IN POLISH NEONATAL AND PAEDIATRIC INTENSIVE CARE UNITS}

M. Migdal' ${ }^{1}$, G. Brozek ${ }^{2}$, J. Zejda ${ }^{2}$, J. Swietlinski ${ }^{3}$

${ }^{1}$ Department of Anaesthesiology and Intensive Care, Children's Memorial Health Institute, Warsaw, ${ }^{2}$ Department of Epidemiology, Silesian University of Medicine, Katowice, ${ }^{3}$ Department of Scientific Information, Children's Memorial Health Institute, Warsaw, Poland

Aim: To describe currently existing in Poland practices and facilities for mechanical ventilation of newborns and children.

Methodology: The study was performed as a part of "The Polish National Survey on Practices in Paediatric and Neonatal Intensive Care" in 2009. The questionnaire referred to ventilatory support was sent to all Polish neonatal (NICUs) and paediatric intensive care units (PICUs). Data collection and statistical analysis was performed by the independent centre.

Results: The overall response rate in the survey was $67 \%$ with 28 PICUs and 41 NICUs participating in the study. On a day of the survey mean number of patients requiring mechanical support was 10 and 7 respectively in PICUs and NICUs. Invasive mechanical ventilation was used in $70 \%$ of patients both in PICUs and NICUs. High frequency oscillation ventilation was more frequently reported in NICUs ( $7 \%$ of patients vs. $2 \%$ ).

Conclusions: Results of the survey may be an important tool for better knowledge on level of ventilatory support providing for newborns and children in Poland. The database and already existing connections could be used in the future for research projects.
1354

\section{PRESSURE SUPPORT VENTILATION AND VOLUME GUARANTEE DURING SURFACTANT THERAPY}

A. López Escobar, I. Llana Martín, P. Touza Pol, S. Bugarini, C. Cantón, M. Fernández Díaz, S. Jimeno Ruiz, M. Benedit Gómez, Comisión de Investigación y Actualización Neonatal

Departamento de Pediatría. Hospital Universitario de Madrid Torrelodones, Universidad San Pablo CEU, Madrid, Spain

Introduction: Intratracheal administration of surfactant is a very common procedure, however it is not well standarised.

Objectives: Complications found during surfactant therapy in Pressure-Support-Ventilation and VolumeGuarantee (PSV/VG) from Dräger-Babylog-8000.

Patients and methods: Descriptive and prospective study in newborns with respiratory distress syndrome to whom surfactant was given in our NeonatalIntensive-Care-Unit during the period of study: 20082009. Curosurf was administrated through a duallumen-endotracheal-tube. Ventilatory mode: PSV/ VG. Ventilator parameters and vital signs before, during and after surfactant administration were monitorised (5 and 10 minutes).

Results: 14 doses of surfactant were given to 12 infants ( 3 of them same patient). 11 of them were preterm (32w, 1892,15gr). 6 weight less than $1500 \mathrm{~g}$. Surfactant was administrated at $21,7 \mathrm{~h}$ of life.

No changes in cardiac rate or oxygen saturation were found during the procedure. Significant differences between the $\mathrm{FiO} 2$ before and 5 minutes $(53,5-32,5 \%)$ $p<0.009$ and 10 minutes $(53,5-28,35 \%) p<0,043$ after the administration of surfactant were recorded. There was no significant difference regarding cardiac rate. Low blood pressure was not detected at any time after surfactant.

None of the complications described in literature in relation to the administration of surfactant (pulmonary bleeding, air escape, apnoea, endotracheal tube obstruction) occurred in any of our cases.

Discussion: Surfactant therapy disminishes the requirements of supplementary oxygen. According to our data, PSV/VG could be a safe option for the administration of intratracheal surfactant as we have not recorded complications during this procedure. However more studies with a higher number of patients are needed to confirm these findings. 